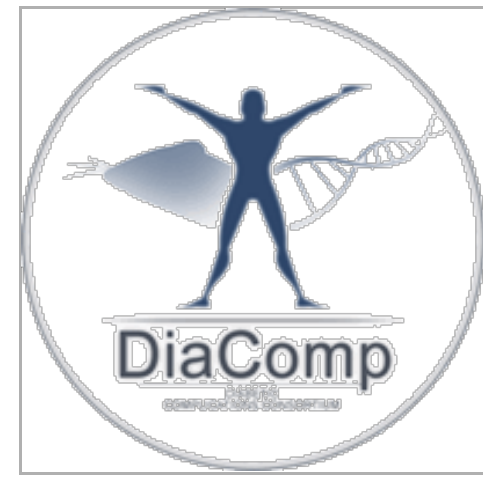

AUG 19, 2019

\section{open $\boldsymbol{\text { ACCESS }}$}

\section{DOI:}

dx.doi.org/10.17504/protocol s.io.33bgqin

\section{External link:}

https://www.diacomp.org/shar ed/document.aspx?

$\mathrm{id}=18 \&$ docType $=$ Protocol

\section{Protocol Citation: Daniel} Teupser, Jan Breslow 2019. Ultracentrifugal separation of VLDL, LDL and HDL. protocols.io

https://dx.doi.org/10.17504/p rotocols.io.33bgqin

License: This is an open access protocol distributed under the terms of the Creative Commons Attribution License, which permits unrestricted use, distribution, and reproduction in any medium, provided the original author and source are credited

Protocol status: Working We use this protocol and it's working

Created: Jun 11, 2019

Last Modified: Aug 19, 2019

PROTOCOL integer ID: 24387

\title{
(3) Ultracentrifugal separation of VLDL, LDL and HDL
}

Daniel Teupser ${ }^{1}$, Jan Breslow $^{1}$

${ }^{1}$ Rockefeller University

Diabetic Complications Consortium

Tech. support email: rmcindoe@augusta.edu

\section{Lili Liang}

\section{ABSTRACT}

\section{Summary:}

This protocol is used to isolate the various lipid fractions from blood plasma using ultracentrifugation. The actual measured concentrations are performed separately once the isolations are complete.

NOTE: This protocol is not applicable for ApoE knockout mice.

\section{Diabetic Complications:}

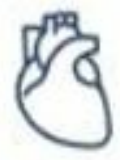

Cardiovascular

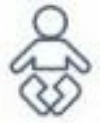

Pediatric Endocrinology Uropathy Wound-Healing 
Keywords:

ultracentrifugation, VLDL, LDL, $\mathrm{HDL}$, cardiovascular, retinopathy, neuropathy, nephropathy, pediatric endocrinology, uropathy, wound-healing

\section{MATERIALS}

MATERIALS

88 Beckman Optima TL tabletop ultracentrifuge Beckman Coulter

88 Beckman 7×20 mm thick walled ultracentrifuge tube Beckman Coulter Catalo \#343621

88 Hamilton Syringe (100 ul) Contributed by users

$88 \mathrm{KBr}$ Solution Contributed by users

88 Phosphate Buffered Saline Contributed by users

\begin{tabular}{|l|c|}
\hline \multicolumn{1}{|c|}{ Reagent/Material } & $\begin{array}{c}\text { Quantity } \\
\text { Required }\end{array}$ \\
\hline Beckman Optima TL tabletop ultracentrifuge & \\
\hline $\begin{array}{l}\text { Beckman 7×20 mm, thick walled } \\
\text { ultracentrifuge tube }\end{array}$ & 2 \\
\hline Hamilton Syringe (100 ul) & 1 \\
\hline KBr Solution & $1 \mathrm{ml}$ \\
\hline Phosphate Buffered Saline & $1 \mathrm{ml}$ \\
\hline
\end{tabular}

\section{SAFETY WARNINGS}

(1) WARNING.

The use of an ultracentrifuge should only be performed by qualified technicians/personnel.

1 Add 60 ul of plasma to Beckman ultracentrifugation tube $(7 \times 20 \mathrm{~mm}$; thick walled; polyallomer; cat. \# 343621).

2 Layer $60 \mathrm{ul}$ of PBS on top of the plasma and place tubes in a TLA100 rotor.

3 Spin for 3 hours Beckman Optima TL tabletop ultracentrifuge at 70,000 rpm, $4^{\circ} \mathrm{C}$. 
$4 \quad$ Using a $100 \mu \mathrm{l}$ Hamilton syringe, carefully remove the bottom $60 \mu \mathrm{l}$ and transfer to a new Beckman tube labeled with the sample number and $A$. Between samples rinse the Hamilton syringe with distilled water.

5 Using a rinsed Hamilton syringe transfer the rest of the sample (upper portion) into a second tube labeled with the sample number and $B$.

6 Add $60 \mu \mathrm{KBr}$ solution (density $=1.12 \mathrm{~g} / \mathrm{ml}$ ) to tube A to make a final density of $1.063 \mathrm{~g} / \mathrm{ml}$ ) and mix 5 to 6 times up and down with the same pipette tip.

$7 \quad$ Layer $60 \mu$ l of PBS on top of the sample in tube B.

8 Spin both $\mathrm{A}$ and $\mathrm{B}$ for $18 \mathrm{~h}$ overnight in the ultracentrifuge at $70,000 \mathrm{rpm}$ at $4 \mathrm{C}$ as above.

9 Using a rinsed $100 \mu \mathrm{l}$ Hamilton syringe remove the bottom $60 \mu \mathrm{l}$ from tube $\mathrm{A}$ and transfer to an Eppendorf tube labeled HDL. Using a rinsed Hamilton syringe transfer the remaining $60 \mu \mathrm{l}$ (upper portion) to an Eppendorf tube labeled LDL.

10 Using a rinsed Hamilton syringe remove the bottom $60 \mu \mathrm{l}$ from tube $\mathrm{B}$ and transfer to the same Eppendorf tube labeled LDL in step 9 above (To recover any LDL contaminating the VLDL preparation after the first ultracentrifugation spin).

11 Using a rinsed Hamilton syringe transfer the remaining $60 \mu$ from tube $B$ to an Eppendorf tube labeled VLDL.

12 Measure cholesterol, triglycerides or phospholipids concentrations in the lipoprotein fractions using their respective protocols. 
NOTE: When determining the lipid concentrations of the lipoprotein fractions, the value for $L D L$ must be multiplied by 2 in order to account for the two-fold higher volume $(120 \mu l)$ in this tube.

The densities of the fractions are as follows:

VLDL $<1.006 \mathrm{~g} / \mathrm{ml}$

LDL, IDL $1.006-1.063 \mathrm{~g} / \mathrm{ml}$

$\mathrm{HDL}>1.063 \mathrm{~g} / \mathrm{ml}$ 